\title{
Candidimonas bauzanensis sp. nov., isolated from soil, and emended description of the genus Candidimonas Vaz-Moreira et al. 2011
}

\author{
Correspondence \\ Rosa Margesin \\ Rosa.Margesin@uibk.ac.at
}

\author{
De-Chao Zhang, ${ }^{1}$ Hans-Jürgen Busse, ${ }^{2}$ Cornelia Wieser, ${ }^{2}$ Hong-Can Liu, ${ }^{3}$ \\ Yu-Guang Zhou, ${ }^{3}$ Franz Schinner ${ }^{1}$ and Rosa Margesin ${ }^{1}$ \\ ${ }^{1}$ Institute of Microbiology, University of Innsbruck, Technikerstrasse 25, A-6020 Innsbruck, Austria \\ ${ }^{2}$ Institute of Bacteriology, Mycology and Hygiene, University of Veterinary Medicine Vienna, \\ Veterinärplatz 1, A-1210 Vienna, Austria \\ ${ }^{3}$ China General Microbiological Culture Collection Center and State Key Laboratory of Microbial \\ Resources, Institute of Microbiology, Chinese Academy of Sciences, Beijing 100101, PR China
}

The genus Candidimonas was proposed by Vaz-Moreira et al. (2011) to accommodate Gram-negative rods that contain Q-8 as the respiratory quinone and summed feature 2 $\left(\mathrm{C}_{14: 0} 3-\mathrm{OH}\right.$ and/or iso- $\left.\mathrm{C}_{16: 1} \mathrm{I}\right), \mathrm{C}_{16: 0}$ and $\mathrm{C}_{18: 1} \omega 7 c$ as the major fatty acids. At the time of writing, the genus Candidimonas includes two species: Candidimonas nitroreducens and Candidimonas humi. The type strains of these species were isolated from sewage sludge compost. In this study, we describe the characterization of a novel bacterium of the genus Candidimonas.

Strain $\mathrm{BZ} \mathrm{9}^{\mathrm{T}}$ was isolated from soil of an industrial site containing high amounts of heavy crude oil and heavy metals in Bozen, South Tyrol, Italy, as previously described (Zhang et al., 2010). Briefly, soil was shaken with sodium

Abbreviations: $A L$, Unidentified aminolipid; $A P L$, aminophospholipid; DPG, diphosphatidylglycerol; PE, phosphatidylethanolamine; PG, phosphatidylglycerol; PME, phosphatidylmonomethylethanolamine.

The GenBank/EMBL/DDBJ accession number for the 16S rRNA gene sequence of strain BZ59 ${ }^{\top}$ is GQ246953.

Two supplementary figures and a supplementary table are available with the online version of this paper. pyrophosphate solution and appropriate dilutions were plated on R2A agar (containing $0.05 \%$ yeast extract, $0.05 \%$ peptone, $0.05 \%$ Casamino acids, $0.05 \%$ glucose, $0.05 \%$ starch, $0.03 \%$ sodium pyruvate, $0.03 \% \mathrm{~K}_{2} \mathrm{HPO}_{4}, 0.005 \%$ $\mathrm{MgSO}_{4}, 1.5 \%$ agar; pH 7; Reasoner \& Geldreich, 1985). Strain $B Z 59^{\mathrm{T}}$ formed white colonies. Strain $\mathrm{BZ} 59^{\mathrm{T}}$ was routinely cultured on R2A agar and stored as a suspension in skim milk $(10 \%, \mathrm{w} / \mathrm{v})$ at $-80{ }^{\circ} \mathrm{C}$. C. nitroreducens SC-089 ${ }^{\mathrm{T}}$, C. humi SC-092 ${ }^{\mathrm{T}}$, Parapusillimonas granuli KCTC $12668^{\mathrm{T}}$ and Pusillimonas ginsengisoli KCTC $22046^{\mathrm{T}}$ were routinely grown on $\mathrm{R} 2 \mathrm{~A}$ agar at $25{ }^{\circ} \mathrm{C}$ and used as reference strains.

DNA of strain $B Z 59^{\mathrm{T}}$ was extracted and purified as described by Sambrook et al. (1989). The 16S rRNA gene was amplified by PCR with the universal primers $27 \mathrm{~F}$ (5'-AGAGTTTGATCCTGGCTCAG-3') and 1541R (5' -AAGGAGGTGATCCAGCCGCA- $3^{\prime}$ ). The amplification products were cloned using the pGEM-T Easy vector system (Promega). Sequencing reactions were carried out by Eurofins MWG Operon (Ebersberg, Germany) using the ABI Big Dye Terminator kit (v3.1) and an automated DNA sequencer (model ABI $3730 \mathrm{XL}$ ). The sequence was 
aligned with sequences retrieved from GenBank and EMBL databases using CLUSTAL_X version 1.8 (Thompson et al., 1997). Neighbour-joining phylogenetic analysis was carried out using MEGA version 4.0 (Tamura et al., 2007). In addition, a maximum-likelihood tree was generated using PHYLIP version 3.69 (Felsenstein, 2009). The neighbour-joining tree (Fig. 1) showed that strain $\mathrm{BZ} 59^{\mathrm{T}}$ clustered with the genus Candidimonas and formed a distinct cluster with C. nitroreducens $\mathrm{SC}-089^{\mathrm{T}}$ and C. humi SC-092 ${ }^{\mathrm{T}}$, with which it exhibited $97.7 \%$ and 97.6\% 16S rRNA gene sequence similarity, respectively. A similar topology was found in the maximum-likelihood tree (Fig. 1).
Morphology of cells grown on R2A agar at $25{ }^{\circ} \mathrm{C}$ was examined using phase-contrast microscopy $(\times 1000$; Diaplan, Leitz) and transmission electron microscopy (Libra 120 EFTEM; Zeiss). Motility was examined using microscopy $(\times 1000)$ and the API M system (bioMérieux). Gram-reaction was tested by Gram-staining and confirmed by $\mathrm{KOH}$ lysis. Catalase activity was determined by bubble production in $3 \%(\mathrm{v} / \mathrm{v}) \mathrm{H}_{2} \mathrm{O}_{2}$ and cytochrome $c$ oxidase activity was determined using $1 \%(\mathrm{w} / \mathrm{v}) \quad \mathrm{N}, \mathrm{N}$, $N^{\prime}, N^{\prime}$-tetramethyl- $p$-phenylenediamine. Physiological and biochemical characteristics and enzyme activities were determined using the API 20 NE, API 20 E and API ZYM systems (bioMérieux) at $25{ }^{\circ} \mathrm{C}$. Amylase, lipase and protease

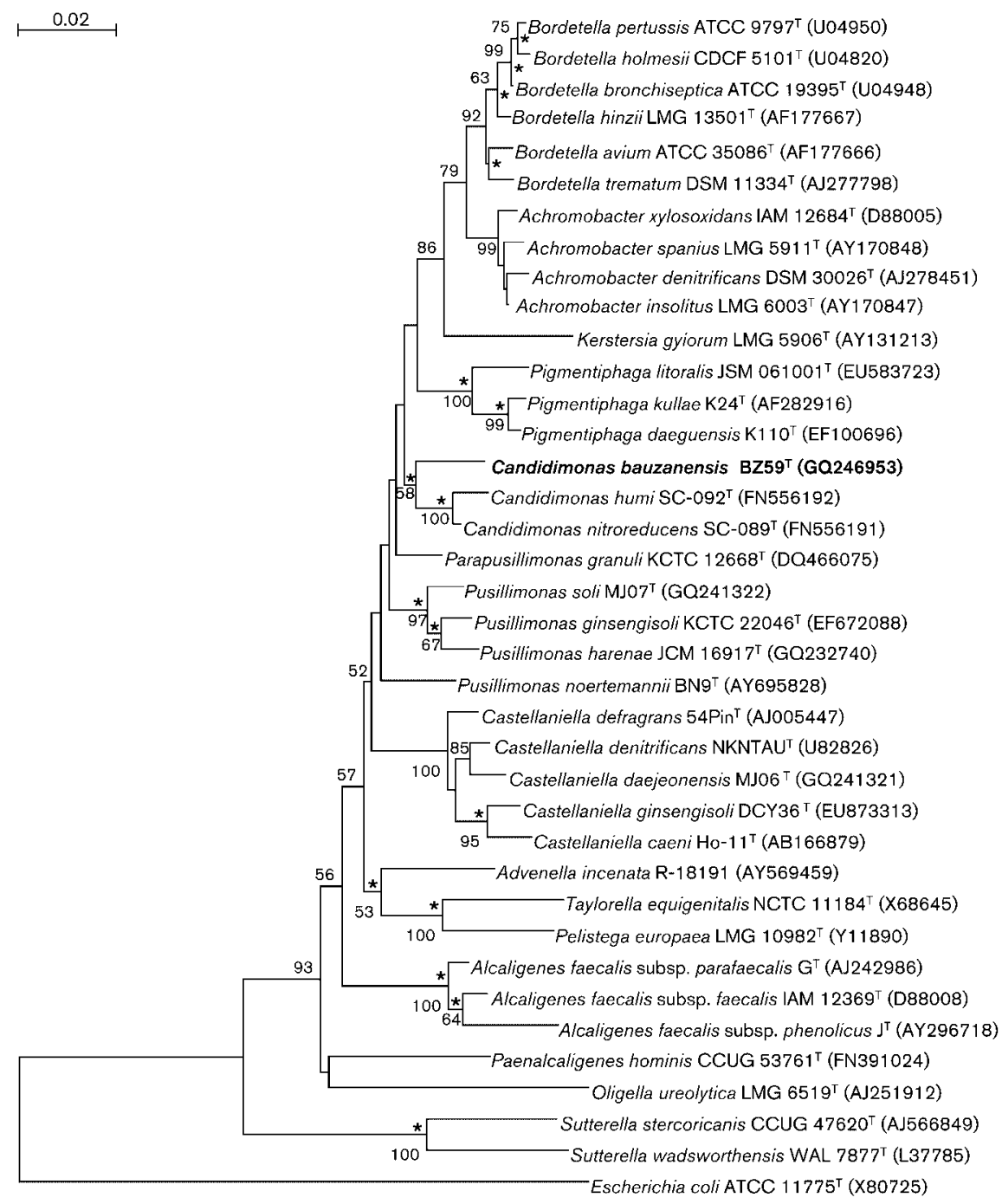

Fig. 1. Neighbour-joining tree, based on $16 \mathrm{~S}$ rRNA gene sequences, showing the phylogenetic position of strain $B Z 59^{\top}$ and representatives of other taxa in the family Alcaligenaceae. Bootstrap values ( $>50 \%$ ) based on 1000 replicates are shown at branch nodes. Asterisks indicate that the corresponding nodes were also recovered in the maximum-likelihood tree. Bar, $2 \%$ sequence divergence. 
activities were also tested on R2A agar supplemented with the appropriate substrates (Margesin et al., 2003). Growth under anaerobic conditions was determined after 7 days at $25{ }^{\circ} \mathrm{C}$ in an anaerobic jar containing Anaerocult A (Merck) to produce anaerobic conditions on nutrient agar (NA; $0.5 \%$ peptone, $0.3 \%$ meat extract, $1.5 \%$ agar; $\mathrm{pH} 7$ ) and R2A agar supplemented with $10 \mathrm{mM} \mathrm{KNO}_{3}$. Growth at $1-45{ }^{\circ} \mathrm{C}$ was assessed on R2A agar and in R2A broth with shaking at 150 r.p.m. Growth at $\mathrm{pH}$ 5-10 (using buffered medium) and with $0-10 \%(\mathrm{w} / \mathrm{v}) \mathrm{NaCl}$ was determined on R2A agar. Growth with trypticase soy agar (TSA; $1.5 \%$ casein peptone, $0.5 \%$ soy peptone, $0.5 \%$ sodium chloride, $1.5 \%$ agar; $\mathrm{pH} 7$ ) was also assessed. All tests were carried out simultaneously with strain $\mathrm{BZ} 59^{\mathrm{T}}$ and the four reference strains. The morphological, physiological and biochemical characteristics of strain $\mathrm{BZ} 59^{\mathrm{T}}$ are given in the species description and the features that differentiate strain $B Z 59^{\mathrm{T}}$ from the reference strains are given in Table 1 .

For fatty acid methyl ester analysis, strain $B Z 59^{\mathrm{T}}$ and the reference strains were grown on TSA at $25{ }^{\circ} \mathrm{C}$ for 3 days after quadrant streak inoculation. All strains agreed in their growing behaviour and cells of comparable physiological age were harvested from the third sectors of the quadrant streaks. The fatty acid methyl esters were extracted and prepared according to the standard protocol of the Sherlock Microbial Identification System (version 6.1; MIDI; Sasser, 1990), using an Agilent 6890N gas chromatograph and were identified using the TSBA database (version 4.10). The fatty acids were determined by the Identification Service of the DSMZ (Braunschweig, Germany). Strain $B Z 59^{\mathrm{T}}$ contained the following cellular fatty acids $(>3 \%): \mathrm{C}_{16: 0}(29.6 \%)$, $\mathrm{C}_{17: 0}$ cyclo $(24.8 \%)$, summed feature $3\left(\mathrm{C}_{16: 1} \omega 7 c\right.$ and/or iso- $\left.\mathrm{C}_{15: 0} 2-\mathrm{OH} ; 20.4 \%\right), \mathrm{C}_{18: 1} \omega 7 c(8.9 \%), \mathrm{C}_{12: 0}(3.8 \%)$, $\mathrm{C}_{12: 0} 2-\mathrm{OH}(2.3 \%), \mathrm{C}_{12: 0} 3-\mathrm{OH}(1.8 \%)$ and summed feature $2\left(\mathrm{C}_{14: 0} 3-\mathrm{OH}\right.$ and/or iso- $\left.\mathrm{C}_{16: 1} \mathrm{I} ; 4.6 \%\right)$ (Table $\mathrm{S} 1$, available in IJSEM Online). The fatty acid composition of strain $\mathrm{BZ} 59^{\mathrm{T}}$ resembled those of the members of the genus Candidimonas (Vaz-Moreira et al., 2011), with the exception that strain $\mathrm{BZ}_{5} 9^{\mathrm{T}}$ contained higher amounts of $\mathrm{C}_{12: 0}$ and lower amounts of summed feature 2 and $\mathrm{C}_{18: 0}$ than C. humi and C. nitroreducens.

Table 1. Phenotypic characteristics that differentiate strain $B Z 59^{\top}$ from its closest phylogenetic neighbours

Strains: 1, BZ59 ${ }^{\mathrm{T}} ;$ 2, C. humi SC-092 ${ }^{\mathrm{T}}$; 3, C. nitroreducens SC-089 ${ }^{\mathrm{T}}$; 4, Parapusillimonas granuli KCTC $12668^{\mathrm{T}}$; 5, Pusillimonas ginsengisoli KCTC $22046^{\mathrm{T}}$. Data were taken from this study unless otherwise stated. All strains are positive for catalase, cytochrome oxidase, leucine arylamidase, naphthol-AS-BI-phosphohydrolase and assimilation of adipic acid. All strains are negative for amylase, protease, lipase (C14), trypsin, $\alpha$ - and $\beta$ galactosidases, $\alpha$ - and $\beta$-glucosidases, $\beta$-glucuronidase, $\alpha$-mannosidase, $\alpha$-fucosidase, $N$-acetyl- $\beta$-glucosaminidase, arginine dihydrolase and assimilation of D-mannitol, $N$-acetylglucosamine, D-mannose, maltose and capric acid. + , Positive; w, weakly positive; - , negative.

\begin{tabular}{|c|c|c|c|c|c|}
\hline Characteristic & 1 & 2 & 3 & 4 & 5 \\
\hline Isolation source ${ }^{\star}$ & $\begin{array}{l}\text { Hydrocarbon- } \\
\text { contaminated soil }\end{array}$ & $\begin{array}{l}\text { Sewage sludge } \\
\text { compost }\end{array}$ & $\begin{array}{c}\text { Sewage sludge } \\
\text { compost }\end{array}$ & $\begin{array}{l}\text { Wastewater- } \\
\text { treatment bioreactor }\end{array}$ & $\begin{array}{l}\text { Soil of a } \\
\text { ginseng field }\end{array}$ \\
\hline $\begin{array}{l}\text { DNA G + C content } \\
(\mathrm{mol} \%)^{*} \dagger\end{array}$ & 61.6 & 65.0 & 64.0 & $67.9 \pm 0.1$ & 57.3 \\
\hline Anaerobic growth & + & W & $\mathrm{W}$ & + & - \\
\hline Motility & + & - & - & + & - \\
\hline \multicolumn{6}{|l|}{ Growth at: } \\
\hline $1-5^{\circ} \mathrm{C}$ & + & - & - & - & - \\
\hline $10{ }^{\circ} \mathrm{C}$ & + & - & - & + & + \\
\hline $\mathrm{pH} 5$ & - & + & + & - & - \\
\hline $\begin{array}{l}\text { End product of nitrate } \\
\text { reduction }\end{array}$ & $\mathrm{N}_{2}$ & - & $\mathrm{NO}_{3}$ & $\mathrm{~N}_{2}$ & $\mathrm{NO}_{3}$ \\
\hline \multicolumn{6}{|l|}{ Enzyme activities } \\
\hline Urease & + & - & - & - & - \\
\hline Alkaline phosphatase & - & + & + & - & - \\
\hline \multicolumn{6}{|l|}{ Assimilation (API $20 \mathrm{NE}$ ) } \\
\hline D-Glucose & + & - & - & - & - \\
\hline L-Arabinose & $\mathrm{W}$ & - & - & - & - \\
\hline Potassium gluconate & + & - & - & - & - \\
\hline Malic acid & + & - & $\mathrm{W}$ & - & + \\
\hline Trisodium citrate & $\mathrm{W}$ & $\mathrm{W}$ & - & - & + \\
\hline Phenylacetic acid & - & + & + & + & + \\
\hline
\end{tabular}

${ }^{\star}$ Data for columns 2 and 3 were obtained from Vaz-Moreira et al. (2011), for column 4 from Kim et al. (2010) and for column 5 from Srinivasan et al. (2010).

$\dagger$ Data for column 1 were obtained by the liquid renaturation method and for columns $2-5$ by HPLC. 
Respiratory quinones were extracted and purified according to Collins (1985) and analysed by HPLC (Wu et al., 1989). The isoprenoid quinone was Q-8. For polyamine and polar lipid analysis, strain $\mathrm{BZ} 59^{\mathrm{T}}$ was grown in PYE medium $(0.3 \%$ yeast extract, $0.3 \%$ peptone; $\mathrm{pH} 7)$ and harvested at the late exponential growth phase. Polyamines were extracted as described by Busse \& Auling (1988) and analysed as described by Busse et al. (1997) using the HPLC apparatus described by Stolz et al. (2007). The polyamine pattern contained putrescine $\left[46.4 \mu \mathrm{mol}\left(\mathrm{g}^{\mathrm{d}} \mathrm{dry} \text { mass }\right)^{-1}\right]$, spermidine $\left[19.6 \mu \mathrm{mol}(\mathrm{g} \text { dry mass })^{-1}\right], 2$-hydroxyputrescine $\left[8.5 \mu \mathrm{mol}\right.$ (g dry mass) $\left.{ }^{-1}\right]$, spermine $[3.3 \mu \mathrm{mol}$ (g dry mass $\left.)^{-1}\right]$ and cadaverine $\left[1.3 \mu \mathrm{mol}\left(\mathrm{g}_{\text {dry mass }}\right)^{-1}\right]$. This polyamine pattern is in agreement with that of other members of the class Betaproteobacteria, which includes the family Alcaligenaceae (Busse \& Auling, 1988). Polar lipids were analysed according to Tindall (1990a, b). The major polar lipids (Fig. S1) were phosphatidylethanolamine (PE), phosphatidylglycerol (PG), phosphatidylmonomethylethanolamine (PME) and diphosphatidylglycerol (DPG). Furthermore, minor amounts of an unidentified aminolipid (AL), an aminophospholipid (APL) and two polar lipids (L1 and L2) were detected. This polar lipid profile exhibited several similarities with those of the genus Candidimonas (Vaz-Moreira et al., 2011). As well as PE, PG and DPG, which have also been detected in other taxa of the family Alcaligenaceae, strain $\mathrm{BZ}^{\mathrm{T}} \mathrm{T}^{\mathrm{T}}$ shared the presence of PME (designated APL1 by Vaz-Moreira et al., 2011) with C. humi and C. nitroreducens. Of the members of the family Alcaligenaceae, a polar lipid showing the same staining and chromatographic behaviour as PME has only been previously reported for $C$. humi and C. nitroreducens and Parapusillimonas granuli (Vaz-Moreira et al., 2011). On the other hand, the presence of AL, L1 and L2 and the absence of additional aminophospholipids clearly distinguished strain $\mathrm{BZ} 9^{\mathrm{T}}$ from the two recognized members of the genus Candidimonas. Considering the close phylogenetic relatedness between the isolate and C. humi and C. nitroreducens, the differences in polar lipid profiles should be considered as indicative of strain $\mathrm{BZ} 59^{\mathrm{T}}$ representing a novel species of the genus Candidimonas rather than a novel genus.

The DNA G $+\mathrm{C}$ content was determined using the thermal denaturation method with Escherichia coli $\mathrm{K}-12$ as the reference. DNA-DNA hybridization was performed by the liquid renaturation method in triplicate, according to De Ley et al. (1970) as modified by Huß et al. (1983). Both experiments were carried out using a model Lambda $35 \mathrm{UV} /$ VIS spectrometer equipped with a temperature program controller (Perkin-Elmer). The DNA G $+\mathrm{C}$ content of strain $\mathrm{BZ} 9^{\mathrm{T}}$ was $61.6 \mathrm{~mol} \%$. The DNA-DNA relatedness values between strain $\mathrm{BZ} 59^{\mathrm{T}}$ and C. nitroreducens $\mathrm{SC}-089^{\mathrm{T}}$ and $C$. humi SC- $092^{\mathrm{T}}$ were $23.7 \pm 2.3 \%$ and $21.5 \pm 3.5 \%$, respectively. These values are much lower than the $70 \%$ threshold value proposed for separation of strains at the species level (Wayne et al., 1987).

Strain BZ59 ${ }^{\mathrm{T}}$ could be differentiated from C. nitroreducens SC- $089^{\mathrm{T}}$ and C. humi SC- $092^{\mathrm{T}}$ by a number of physiological properties, such as motility, ability to grow at $1-10{ }^{\circ} \mathrm{C}$, urease activity, ability to assimilate glucose, potassium gluconate and malic acid and inability to assimilate phenylacetic acid and to produce alkaline phosphatase. In addition, the isolate differed from Parapusillimonas granuli KCTC $12668^{\mathrm{T}}$ by its ability to grow at $1-5^{\circ} \mathrm{C}$ and urease activity and further from Pusillimonas ginsengisoli KCTC $22046^{\mathrm{T}}$ by motility and ability to grow under anaerobic conditions. The ability to produce the highest cell yields at $1-5{ }^{\circ} \mathrm{C}$ in liquid culture demonstrated the psychrophilic character of strain $\mathrm{BZ} 59^{\mathrm{T}}$. We use the term psychrophile as a general term that describes a microorganism that grows in a cold environment (Margesin et al., 2008), since the use of growth rates to define the optimum growth temperature, as described by Morita (1975), has been shown to be ambiguous and inappropriate (Cavicchioli, 2006; Margesin, 2009).

The polar lipid profile of strain $\mathrm{BZ} 59^{\mathrm{T}}$ showed some striking similarities with those of the two recognized members of the genus Candidimonas, which were phylogenetically more closely related to each other than to strain $\mathrm{BZ}^{2} 9^{\mathrm{T}}$ (Fig. 1) and which also exhibited higher $16 \mathrm{~S}$ rRNA gene sequence similarity with each other $(99.1 \%)$ than with strain $\mathrm{BZ} 59^{\mathrm{T}}$ (97.6-97.7\%). Similar degrees of differences were also seen in the polar lipid profiles: those of the two recognized members of the genus Candidimonas were almost indistinguishable, whereas strain $B Z 59^{\mathrm{T}}$ lacked two of the four APLs listed in the genus description (Vaz-Moreira et al., 2011). However, from our point of view, these differences should be considered as species specific and not indicative of a novel genus. Hence, we propose that strain $\mathrm{BZ}^{\mathrm{T}} 9^{\mathrm{T}}$ is assigned to the genus Candidimonas as representing a novel species, Candidimonas bauzanensis sp. nov., and that the genus description is emended.

\section{Emended description of the genus Candidimonas Vaz-Moreira et al. 2011}

The description of the genus Candidimonas is as given by Vaz-Moreira et al. (2011) with the following modifications. Mesophilic or psychrophilic. Cells are motile or nonmotile. Urease and alkaline phosphatase activity are species dependent. The predominant cellular fatty acids are $\mathrm{C}_{16: 0}$, $\mathrm{C}_{17: 0}$ cyclo and summed feature $3\left(\mathrm{C}_{16: 1} \omega 7 c\right.$ and/or iso$\mathrm{C}_{15: 0}$ 2-OH). The polar lipid profile contains phosphatidylethanolamine, phosphatidylglycerol, phosphatidylmonomethylethanolamine and diphosphatidylglycerol. Variable numbers of unidentified aminophospholipids are detectable. The type species is Candidimonas nitroreducens.

\section{Description of Candidimonas bauzanensis sp. nov.}

Candidimonas bauzanensis (bau.zan.en'sis. N.L. fem. adj. bauzanensis referring to Bauzanum medieval Latin name of Bozen/Bolzano, a city in South Tyrol, Italy, where the type strain was isolated). 
Cells are Gram-negative, facultatively anaerobic rods (0.7$0.9 \times 1.2-1.9 \mu \mathrm{m}$ after 3 days at $25{ }^{\circ} \mathrm{C}$ on R2A agar) and motile by polar flagella (Fig. S2). Colonies on R2A agar are creamy white, smooth, round and convex with entire margins (after 3 and 5 days at $25{ }^{\circ} \mathrm{C}, 1-1.2$ and $1.5 \mathrm{~mm}$ in diameter, respectively). Nitrate is reduced to nitrogen gas. Catalase- and cytochrome oxidase-positive. Grows well at $1-30{ }^{\circ} \mathrm{C}$ in $\mathrm{R} 2 \mathrm{~A}$ broth and on R2A agar, grows weakly at $37^{\circ} \mathrm{C}$ and does not grow at $42{ }^{\circ} \mathrm{C}$. In liquid culture, growth is fastest at $25-30{ }^{\circ} \mathrm{C}$ and cell density is highest at $1-5{ }^{\circ} \mathrm{C}$. Grows at $\mathrm{pH} 6-8$ and with $0-3 \%(\mathrm{w} / \mathrm{v}) \mathrm{NaCl}$. Grows on NA and TSA. Negative for indole production from tryptophan, $\mathrm{H}_{2} \mathrm{~S}$ production, citrate utilization and aesculin and gelatin hydrolysis. Positive for urease, leucine arylamidase, esterase (C4) and naphthol-AS-BI-phosphohydrolase, weakly positive for esterase lipase (C8) and acid phosphatase, and negative for arginine dihydrolase, lysine dihydrolase, ornithine dihydrolase, tryptophan deaminase, alkaline phosphatase, amylase, protease (skimmed milk), trypsin, $\alpha$-chymotrypsin, lipase (C14), $N$-acetyl- $\beta$-glucosaminidase, $\alpha$ - and $\beta$-galactosidases, $\beta$-glucuronidase, $\alpha$ - and $\beta$-glucosidases, $\alpha$-mannosidase and $\alpha$-fucosidase. Assimilates D-glucose, adipic acid, malic acid, potassium gluconate, trisodium citrate (weakly) and L-arabinose (weakly), but does not assimilate D-mannose, D-mannitol, maltose, $\mathrm{N}$-acetylglucosamine, capric acid or phenylacetic acid. Does not ferment D-glucose, D-mannitol, sucrose, inositol, D-sorbitol, L-rhamnose, melibiose, amygdalin or L-arabinose. The polyamine pattern is composed of major amounts of putrescine and spermidine and minor amounts of 2-hydroxyputrescine, spermine and cadaverine. The isoprenoid quinone is Q-8. The major polar lipids are phosphatidylethanolamine, phosphatidylglycerol, phosphatidylmonomethylethanolamine and diphosphatidylglycerol. Minor amounts of one unidentified aminolipid, one aminophospholipid and two polar lipids are also detected. The major fatty acids are $\mathrm{C}_{16: 0}, \mathrm{C}_{17: 0}$ cyclo and summed feature $3\left(\mathrm{C}_{16: 1} \omega 7 c\right.$ and/or iso- $\left.\mathrm{C}_{15: 0} 2-\mathrm{OH}\right)$.

The type strain is $\mathrm{BZ} 59^{\mathrm{T}}\left(=\mathrm{DSM} 22805^{\mathrm{T}}=\mathrm{LMG} 26046^{\mathrm{T}}\right.$ $=$ CGMCC $1.10190^{\mathrm{T}}$ ), isolated from soil from an industrial site in Bozen, South Tyrol, Italy. The DNA G + C content of the type strain is $61.6 \mathrm{~mol} \%$.

\section{Acknowledgements}

We are grateful to Dr Célia M. Manaia and Dr Deok-Chun Yang for providing us with the type strains of C. nitroreducens and C. humi, and Parapusillimonas granuli and Pusillimonas ginsengisoli, respectively. This research work was supported by the Autonome Provinz Bozen, Südtirol. We are grateful to W. Salvenmoser (Institute of Zoology, University of Innsbruck) for performing transmission electron microscopy. We thank P. Thurnbichler and J. Mair for technical assistance.

\section{References}

Busse, H.-J. \& Auling, G. (1988). Polyamine pattern as a chemotaxonomic marker within the Proteobacteria. Syst Appl Microbiol 11, 1-8.
Busse, H.-J., Bunka, S., Hensel, A. \& Lubitz, W. (1997). Discrimination of members of the family Pasteurellaceae based on polyamine patterns. Int J Syst Bacteriol 47, 698-708.

Cavicchioli, R. (2006). Cold-adapted archaea. Nat Rev Microbiol 4, 331-343.

Collins, M. D. (1985). Isoprenoid quinone analysis in classification and identification. In Chemical Methods in Bacterial Systematics, pp. 267-287. Edited by M. Goodfellow \& D. E. Minnikin. London: Academic Press.

De Ley, J., Cattoir, H. \& Reynaerts, A. (1970). The quantitative measurement of DNA hybridization from renaturation rates. Eur $J$ Biochem 12, 133-142.

Felsenstein, J. (2009). PHYLIP (phylogeny inference package), version 3.69. Distributed by the author. Department of Genome Sciences, University of Washington, Seattle, USA.

Huß, V. A. R., Festl, H. \& Schleifer, K. H. (1983). Studies on the spectrophotometric determination of DNA hybridization from renaturation rates. Syst Appl Microbiol 4, 184-192.

Kim, Y.-J., Kim, M. K., Im, W.-T., Srinivasan, S. \& Yang, D.-C. (2010). Parapusillimonas granuli gen. nov., sp. nov., isolated from granules from a wastewater-treatment bioreactor. Int J Syst Evol Microbiol 60, 1401-1406.

Margesin, R. (2009). Effect of temperature on growth parameters of psychrophilic bacteria and yeasts. Extremophiles 13, 257-262.

Margesin, R., Gander, S., Zacke, G., Gounot, A. M. \& Schinner, F. (2003). Hydrocarbon degradation and enzyme activities of coldadapted bacteria and yeasts. Extremophiles 7, 451-458.

Margesin, R., Schinner, F., Marx, J. C. \& Gerday, C. (editors) (2008). Psychrophiles: from Biodiversity to Biotechnology. Berlin, Heidelberg: Springer.

Morita, R. Y. (1975). Psychrophilic bacteria. Bacteriol Rev 39, 144-167.

Reasoner, D. J. \& Geldreich, E. E. (1985). A new medium for the enumeration and subculture of bacteria from potable water. Appl Environ Microbiol 49, 1-7.

Sambrook, J., Frisch, E. F. \& Maniatis, T. (1989). Molecular Cloning: a laboratory manual, 2nd edn. Cold Spring Harbor, NY: Cold Spring Harbor Laboratory.

Sasser, M. (1990). Identification of bacteria by gas chromatography of cellular fatty acids, MIDI Technical Note 101. Newark, DE: MIDI Inc.

Srinivasan, S., Kim, M. K., Sathiyaraj, G., Kim, Y.-J. \& Yang, D.-C. (2010). Pusillimonas ginsengisoli sp. nov., isolated from soil of a ginseng field. Int J Syst Evol Microbiol 60, 1783-1787.

Stolz, A., Busse, H.-J. \& Kämpfer, P. (2007). Pseudomonas knackmussii sp. nov. Int J Syst Evol Microbiol 57, 572-576.

Tamura, K., Dudley, J., Nei, M. \& Kumar, S. (2007). MEGA4: molecular evolutionary genetics analysis (MEGA) software version 4.0. Mol Biol Evol 24, 1596-1599.

Thompson, J. D., Gibson, T. J., Plewniak, F., Jeanmougin, F. \& Higgins, D. G. (1997). The CLUSTAL_X windows interface: flexible strategies for multiple sequence alignment aided by quality analysis tools. Nucleic Acids Res 25, 4876-4882.

Tindall, B. J. (1990a). A comparative study of the lipid composition of Halobacterium saccharovorum from various sources. Syst Appl Microbiol 13, 128-130.

Tindall, B. J. (1990b). Lipid composition of Halobacterium lacusprofundi. FEMS Microbiol Lett 66, 199-202.

Vaz-Moreira, I., Figueira, V., Lopes, A. R., De Brandt, E., Vandamme, P., Nunes, O. C. \& Manaia, C. M. (2011). Candidimonas nitroreducens gen. nov., sp. nov. and Candidimonas humi sp. nov., isolated from sewage sludge compost. Int J Syst Evol Microbiol 61, 2238-2246. 
Wayne, L. G., Brenner, D. J., Colwell, R. R., Grimont, P. A. D., Kandler, O., Krichevsky, M. I., Moore, L. H., Moore, W. E. C., Murray, R. G. E. \& other authors (1987). International Committee on Systematic Bacteriology. Report of the ad hoc committee on reconciliation of approaches to bacterial systematics. Int J Syst Bacteriol 37, 463-464.
Wu, C., Lu, X., Qin, M., Wang, Y. \& Ruan, J. (1989). Analysis of menaquinone compound in microbial cells by HPLC. Microbiology [English translation of Microbiology (Beijing)] 16, 176-178.

Zhang, D.-C., Schinner, F. \& Margesin, R. (2010). Pedobacter bauzanensis sp. nov., isolated from soil. Int J Syst Evol Microbiol 60, 2592-2595. 